\title{
Evaluation of Pharmaceutical Marketing and its Impact: A Case Study of Karachi, Sindh, Pakistan
}

\author{
Saira Shahnaz ${ }^{1 *}$, Mudassar Iqbal Arain ${ }^{2}$, Ramesha Anwar ${ }^{3}$, Jibran Khan ${ }^{4}$ \\ 1. Department of Pharmacy Practice, Faculty of Pharmacy, Ziauddin University Karachi, Pakistan. \\ 2. Department of Pharmacy Practice, Faculty of Pharmacy, University of Sindh, Jamshoro, Pakistan. \\ 3. Department of Pharmacy Practice, Faculty of Pharmacy, University of Karachi, Pakistan. \\ 4. Department of Pharmaceutics, Faculty of Pharmacy, University of Sindh, Jamshoro, Pakistan.
}

*Corresponding author's E-mail: msairakhan13022@gmail.com

Received: 08-06-2020; Revised: 14-08-2020; Accepted: 23-08-2020.

DOI: $10.47583 /$ ijpsrr.2020.v64i01.004 \begin{abstract}
The objective of this study is to determine the effects of pharmaceutical marketing and its influence on doctors. Cross sectional study was conducted and non-probability sampling technique was used to compile data. Questionnaire survey was collected from 216 practicing physicians during the June 2019 to February 2020. SPSS version 24 was used to analyze the data statistically. Percentage and Frequency were calculated for the qualitative variable; while mean and standard deviation were calculated for the quantitative variables. This study revealed that pharmaceutical marketing is correlated to physicians' prescribing manner, majority of the promotional tools were tested to motivate doctors, such as visits of medical representatives, drug sample, high and low-cost incentives, sponsored for continuing medical education and travel. Out of total participants, one hundred sixty (74\%) physicians filled the questionnaire completely. Male practicing doctors delight to participate in survey questionnaire $145(67 \%) .71 .4 \%$ of the Physicians met pharmaceutical medical representative weekly, and $6 \%$ daily. $85.6 \%(A=50.9 \%, B=34.7 \%)$ physicians accepted free drug samples, 95.3\%( $A=87 \%, B=8.3 \%)$ accepted low-cost gifts or stationery and $62.4 \%(A=51.8 \%, B=10.6 \%)$ accepted sponsorship by pharmaceutical companies for continuing medical education regularly. $14.4 \%$ of physicians never accepted any benefits. $97.6 \%(A=91.6 \%, B=6 \%)$ physicians believed that they received sufficient knowledge from the medical representatives regularly and physicians declared that their prescribing pattern depend on the visits of medical representatives.92.1\% ( $A=72.7 \%, B=19.4 \%)$ physicians accepted high cost gifts,81.4\%( $A=66.2 \%, B=15.2 \%)$ took sponsorship for travel and $62.4 \%(A=56.9 \%, B=19.4 \%)$ physicians accepted subscription for journals. Avoidance of companies' sponsorship and high cost gifts lead to rational prescribing pattern. Whereas, sufficient information from medical representatives, medical seminars and conferences and acceptance of gifts lead to alter prescribing manner of physicians.
\end{abstract}

Keywords: Medical representatives, Pharmaceutical marketing. Prescribing manner.

\section{INTRODUCTION}

$\mathrm{P}$ harmaceutical marketing directly rely on doctors which are getting more attention day by day. Many pharmaceutical industries adopted different tools for marketing ${ }^{1}$, like free drug samples, subscription of journal ${ }^{2}$, printed pamphlets, medical equipment and other incentive that aided them to increase the acceptance of their pharmaceutical products. ${ }^{3}$ Approximately $84 \%$ of pharmaceutical marketing strives directed to doctors. ${ }^{2}$ The pattern of pharmaceutical marketing is distinct from country wise due to national characteristics but pharmaceutical company has an international nature. ${ }^{4}$ Pharmaceutical industries focus on doctors by providing promotion activities by determining where to focus the strive more to increase their benefits and by selecting the best tool to prevail doctors which protect from unnecessary expenditure. ${ }^{5}$ Profitability was primary focus of the pharmaceutical companies. Doctors required to stay free from external influence regarding to patients' health. ${ }^{6}$ Ethical principles and rules would be helpful for both pharmaceutical companies as well as doctors. These principles also helpful in criticism and morally difficult situation that what action they could take against them. ${ }^{7}$
The four basic ethical principles are mostly used in the business ethic literatures include egoism(egotism), ${ }^{8}$ deontology, utilitarianism and social justice. ${ }^{9}$ The success of brand depended on prescribing behavior of the doctors and prescription also effect on pharmaceutical sale and pharmaceutical marketing. ${ }^{10}$ Monitoring of prescribing practice of every doctor is required for successful relationship marketing program and it would be sustain profitable. ${ }^{11}$

\section{METHODOLOGY}

Data of 216 physicians were collected by non-probability sampling technique. Cross sectional study was conducted and questionnaire was handed over to 216 practicing doctors who were working in Karachi. However, 160 (74\%) physician took a part in the study and completely filled questionnaire. Questionnaire was design prior to data collection. Twenty- one doctors undertook the per-testing questionnaire and their data was not included in final analysis. The study was carried out from 15 January 2019 to 15 June 2019. SPSS version 22.0 was used for data analysis. Percentage and Frequency were calculated for the qualitative variable; while mean and standard deviation were calculated for the quantitative variables. 


\section{RESULTS}

Out of total Practicing physicians, one hundred sixty (74\%) physicians filled the questionnaire completely. Male practicing doctors delight to participate in survey questionnaire $145(67 \%)$. $71.4 \%$ of the Physicians met pharmaceutical medical representative weekly, and $6 \%$ daily. $85.6 \%(A=50.9 \%, B=34.7 \%)$ physicians accepted free drug samples, $95.3 \%(A=87 \%, B=8.3 \%)$ accepted low-cost gifts or stationery and $62.4 \%(A=51.8 \%, B=10.6 \%)$ accepted sponsorship by pharmaceutical companies for continuing medical education regularly. $14.4 \%$ of physicians never accepted any benefits. $97.6 \%(A=91.6 \%, B=6 \%)$ physicians believed that they received sufficient knowledge from the medical representatives regularly and physicians declared that their prescribing pattern depend on the visits of medical representatives. 92.1\% $(A=72.7 \%, B=19.4 \%)$ physicians accepted high cost gifts, $81.4 \%(A=66.2 \%$, $B=15.2 \%)$ took sponsorship for travel and $62.4 \%(A=56.9 \%$, $B=19.4 \%)$ physicians accepted subscription for journals.

Table 1 shows pharmaceutical marketing correlated to doctors prescribing behavior.

This table 1 indicates that pharmaceutical companies use different pharmaceutical tools to promote their brands and there is substantial correlation in between marketing and physicians' prescribing pattern. Doctors accepted that different promotional tools influenced them to prescribing behavior. Figure 1 shows the acceptance rate of gift that influence on physicians' prescribing pattern.

Table 1: The effects of incentive/ promotional tools on physicians' prescribing pattern

\begin{tabular}{|l|c|c|c|}
\hline Pharmaceutical marketing tool & Always accepted = A & Sometime accepted=B & Never accepted=C \\
\hline Visit of medical representative & $198(91.6 \%)$ & $13(6 \%)$ & $5(2.3 \%)$ \\
\hline Free drug samples & $110(50.9 \%)$ & $75(34.7 \%)$ & $31(14.3 \%)$ \\
\hline Medical equipment & $178(82.4 \%)$ & $24(11.11 \%)$ & $14(6.5 \%)$ \\
\hline High cost recreational gifts like laptop, mobile and LCD & $157(72.7 \%)$ & $42(19.4 \%)$ & $17(7.8 \%)$ \\
\hline Stationery (branded pen, pad etc) & $188(87 \%)$ & $18(8.3 \%)$ & $10(4.6 \%)$ \\
\hline Sponsorship for travel & $143(66.2 \%)$ & $33(15.2 \%)$ & $40(18.5 \%)$ \\
\hline Subscription of journals & $123(56.9 \%)$ & $42(19.4 \%)$ & $51(23.6 \%)$ \\
\hline $\begin{array}{l}\text { Participation by company in continuation of medical } \\
\text { education/ research }\end{array}$ & $112(51.8 \%)$ & $23(10.6 \%)$ & $81(37.5 \%)$ \\
\hline
\end{tabular}

Figure 1: The acceptance rate of gift that influence on physicians' prescribing pattern

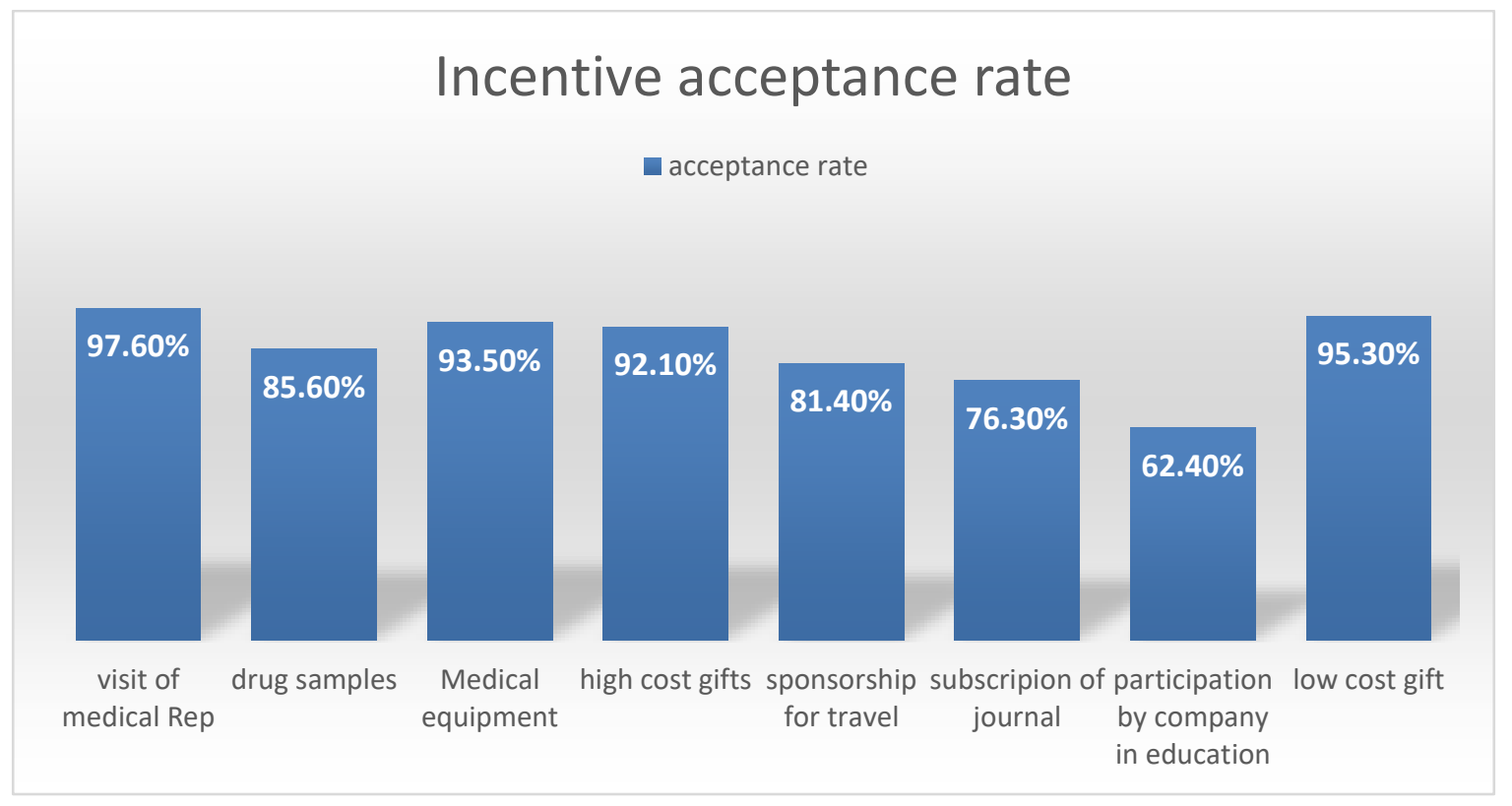

\section{DISCUSSION}

Researchers investigated that physicians mostly depended on commercial source of information rather than patient's need. Source of information from detailers sometime misleading the physicians. Promotional tools impact on physicians such as free drug samples, visits of medical representatives with gifts, participation in continuing medical research and sponsorship for tours but the visit of medical representatives consider as the most powerful tool. ${ }^{12,} 13$ The results of this study showed that doctors prefer to receive low cost gift but continuous supply of incentive at every visit is unethical (95.3\%). The low 
percentage of doctors (4\%) who refused to accept incentives that indicate they realize that acceptance of gifts is not ethical. Lebanese doctors are conscious about gift acceptance policy they accept small and low- cost gifts but it is not permissible according to 2016 code of ethics for medicinal products. ${ }^{14}$ whereas, in other studies, for example: Saudi Arabia and Austria, higher percentage approximately $66-80 \%$ of doctors receive gifts from pharmaceutical companies. ${ }^{15,16}$ This study found that most of the Pakistanis physicians accept high cost gifts (92.1\%) and they consider as it is not unethical. Empirical investigation suggested that younger physicians easily influenced by pharmaceutical promotional tools as compared to older one. Older physicians oppose to utilize the new technologies and new medicines. Same results are found by Peay and Peay's study in 1994. ${ }^{17}$ This study showed that younger physicians are more innovative as compared to older ones. Highest percentage of physicians perceive that low-cost gifts do not change prescribing manner but high-cost incentive could do so. ${ }^{18}$ This indicated that physicians are aware of ethical values. It was found in this study that most of the doctors accepted free sample of medicine $(85.7 \%)$. The free drug samples distribute into poor patients who are unable to afford these medicines.

\section{CONCLUSION}

This study demonstrated that the acceptance of gifts, participation in sponsorship in medical education and adequate information from medical representatives altered the way of prescribing medicines and also considered as unethical practice while most of the physicians used free drug sample to treat poor patients.

\section{REFERENCES}

1. Chiu, H. Selling drugs: marketing strategies in the pharmaceutical industry and their effect on healthcare and research. Explorations. Undergraduate Research, 8, 2005, 89-94.

2. Marco CA, Moskop JC, Solomon RC, Geiderman JM, Larkin GL. Gifts to physicians from the pharmaceutical industry: an ethical analysis. Ann Emerg Med., 48(5), 2006, 513-521. doi: 10.1016/j.annemergmed.2005.12.013.

3. Goyal R, Pareek P. A review article on prescription behavior of doctors, influenced by the medical representative in Rajasthan, India. IOSR J Bus Manage., 8(1), 2013, 56-60. doi: 10.9790/487X-0815660

4. De Laat E, Windmeijer F, Douven RCMH. How does pharmaceutical marketing influence doctors' prescribing behaviour? Den Haag: CPB; 2002
5. Tahmasebi N, Kebriaeezadeh A. Evaluation of factors affecting prescribing behaviors, in Iran pharmaceutical market by econometric methods. Iran J Pharm Res., 14(2), 2015, 651.

6. Lamont J, Favor C. Handbook of political theory. 2004. Distributive justice; p. 1.

7. Mack P. Utilitarian ethics in healthcare. Int J Comput Integr Manuf., 12(3), 2004, 63-72.

8. Lantos GP. In Defense of advertising: arguments from reason, ethical egoism, and laissez-faire capitalism; 1995.

9. Kirkpatrick J. Ethical Theory in Marketing. In: Marketing Education: Challenges, Opportunities and Solutions: Proceedings of the Western Marketing Educators' Association Conference; 1989. p. 50-3

10. Broderick A. Role theory and the management of service encounters. Serv Ind J., 19(2), 1999, 117-131. doi: 10.1080/02642069900000022

11. Sheth JN, Parvatiyar A. Relationship marketing in consumer markets: antecedents and consequences. J Acad Mark Sci. 23(4), 1995, 255-271. doi: 10.1177/009207039502300405

12. Avorn J, Chren M, Hartley R. Scientific versus commercial sources of influence on the prescribing behavior of physicians. Am J Med., 73(1), 1982, 4-8. doi: 10.1016/00029343(82)90911-1.

13. Ziegler MG, Lew P, Singer BC. The accuracy of drug information from pharmaceutical sales representatives. JAMA., 273(16), 1995, 1296-1298. doi: 10.1001/jama.1995.03520400066047.

14. The Lebanese Ministry of Public Health (MOPH), 2016, The Lebanese Code of Ethics: a New Milestone.

15. McNeill PM, Kerridge IH, Henry DA, Stokes B, Hill SR, Newby $D$, et al. Giving and receiving of gifts between pharmaceutical companies and medical specialists in Australia. Intern Med J., 36(9), 2006, 571-578. doi: 10.1111/j.1445-5994.2006.01151.x

16. Alosaimi F, Alkaabba A, Qadi M, Albahlal A, Alabdulkarim Y, Alabduljabbar $\mathrm{M}$, et al. Acceptance of pharmaceutical gifts. Variability by specialty and job rank in a Saudi healthcare setting. Saudi Med J., 34(8), 2013, 854-860.

17. Peay MY, Peay ER. Innovation in high risk drug therapy. Soc Sci Med., 39(1), 1994, 39-52. doi: 10.1016/02779536(94)90164-3

18. Brennan TA, Rothman DJ, Blank L, Blumenthal D, Chimonas $\mathrm{SC}$, Cohen JJ, et al. Health industry practices that create conflicts of interest: a policy proposal for academic medical centers. JAMA. 295(4), 2006, 429-433. doi: 10.1001/jama.295.4.429.

Source of Support: None declared.

Conflict of Interest: None declared.

For any question relates to this article, please reach us at: editor@globalresearchonline.net

New manuscripts for publication can be submitted at: submit@globalresearchonline.net and submit_ijpsrr@rediffmail.com 